ScIDice

International Journal of Natural Disasters \& Health Security (IJNHS)

ISSN 2572-7540

\section{Global Impact of COVID-19 Pandemic}

Roqaiya Perween ${ }^{*}$

Department of Social Work, Aligarh Muslim University, Aligarh, 202002. India.

\title{
Abstract
}

In order to come up with an overview to statistical analysis of the major deadly corona virus disease, the paper provides a critical assessment of global situation of COVID-19 pandemic. In order to come up with a perceptive result, a complete collection of 90 days records (WHO situation reports) of the pandemic have been studied and relevant information have extracted to prepare a working model of dataset. Several statistical measures such as regression, variance, distributions, t-test and ANOVA test have been conducted to understand and explore the ongoing situations and to predict the fore-coming scenario, rate of growth and possible risk assessment of the transmission. Apart from this, an inclusive model of time series analysis of each case has been prepared to predict the expected time for which the pandemic can sustain or rise eventually. It has concluded that the pandemic has suffered from three different phases of transmission, the linear, the non-increasing and exponent. At the end of the paper, the rate of growth along with the growth estimation curve of each case (in general a model) has been developed to estimate the maxima and minima of fluctuation. To identify the asymptotic growth and expected parity index of models, graphical representation of linear and relative growth between the models has provided.

Keywords: COVID-19; WHO; Asymptotic Increase; ANOVA; Variance; Rate of Growth; Social Distancing; Droplet Transmission; SARS-CoV-2; Expected Parity Index.

\section{Introduction}

The official name given to $2019-\mathrm{nCoV}$ is SARS-CoV-2 and is designated COVID-19 for the outbreak. After Severe Acute Respiratory Syndrome (SARS), and Middle East Respiratory Syndrome (MERS), this is the third severe outbreak of Corona virusin less than 20 years following Severe Acute Respiratory Syndrome (SARS), and Middle East Respiratory Syndrome (MERS) [18-20]. In 2019, a new Corona virus was recognized as the source of a disease outbreak that occurred in China. A virus is a submicroscopic infectious agent, which only synthesizes inside an organism's living cells. Vertebrateslike humans, birds, bats, snakes, mice and other wildlife are broadly infected with the Corona virus [48]. Corona viruses belong to theclass of viruses capable of developing diseases like common cold. The disease it triggers is called Corona Virus Disease-2019(COVID-19) [7]. In March 2020 World Health Organization (WHO) announced COVID-19 outbreak as a pandemic. The pandemic was tracked and controlled by the United States Centers for Control and Prevention of Disease (CDC) and the WHO. Recommendations were issued by both associations for avoiding and manage the outbreak. The COVID-19 outbreak has been designated as the sixth foreign public health emergency by WHO $[4,48]$.

Corona viruses are of the subfamily Orthocoronavirinae, genus Coronaviridae, class Nidovirales, and are single-stranded, positive-sense enveloped RNA viruses. These four Corona viruses are commonly transmitted among humans $(\mathrm{HCoV}-229 \mathrm{E}, \mathrm{HCoV}-$ OC43, HCoV-NL63, and HCoV-HKU1) who cause the common cold. The 2019 new, low pathogenic and highly transmissible Corona virus (2019-nCoV), also known as SARS-CoV-2, is the newly described virus that transmits contamination through village states and countries, regardless of boundaries $[1,2]$. The outbreak of COVID-19 originated from China is continuing to expand to other nations. Thus, the preventing measures that the world has taken to deter the spread of $2019-\mathrm{nCoV}$ are by washing hands, using face mask, preventing interaction with sick people and often cover the face when coughing or sneezing with hands or cloth or using a correct cough or sneeze mark during travel or in gatherings. The most important aspects of avoiding the transmission of the infection through methods are educating people with the correct knowledge about the illness, training them the required manners to cough and sneeze and taking care as per the advisories [21]. It is therefore important that the people are provided

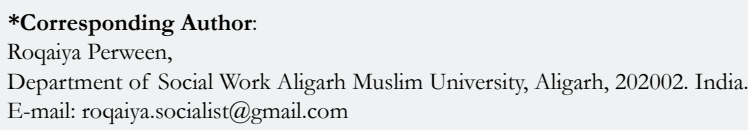


financial as well as psychological assistance [3, 4]. The dissemination of this rare respiratory disorder globally and rising spread of pathogen $(2019 \mathrm{nCoV})$ creates significant questions regarding the course of the December 2019 epidemic in China. Italy reported about $19.44 \%$ of cases, $22.83 \%$ of cases were registered in China, followed by the USA and Spain with $15.44 \%$ and $1182 \%$ respectively [45-47]. Subsequently, by the end of March 2020, COVID-19 affected about $0.16 \%$ of humans in India [5], a hierarchical taxonomy of family of corona virus is shown in Table I.

Finland, India and the Philippines have the first confirmed COVID-19 cases, everyone having travel records to Wuhan. Ministry of Health and Family Welfare took an immediate emergency step to prevent the disease, which included isolation of suspected individuals, surveillance of associates [44]. Additional successful travel limitation measures will help monitor the spread of the disease in certain parts of India [17]. China's overall death rate has increased to $17.98 \%$. Although $37.37 \%$ of the death rate in Italy is very high as compared to all other countries. But the condition in India is very different from other countries, as the mortality levels tend to be just $0.05 \%$ at the initial level. In India, the cumulative number of cases of novel corona virus increased to 553 (25-032020) [6].

\section{Genesis Of Covid-19}

The first reported corona virusescase in the world was in 1960s. The period of its life is not specified. Most commonly it is infected with moderate disease an extremely virulent form occurs after every few years. The pathogenesis of such deadly epidemic is unclear. A cluster of cases of unexplained etiological viral pneumonia, now recognized as SARS-CoV-2 pneumonia, occurred in Wuhan, Hubei Province and was confirmed to health authorities on 29 December 2019 [43]. This epidemic was correlated with a wide demand for seafood and livestock. The condition surrounding SARS-CoV-2 is rapidly changing. According to China's $\mathrm{Na}$ - tional Health Commission (NHC) report on February 17, 2020, a total of 72,436 cases in the Chinese mainland were reported, including 11,741 severe cases and 1868 deaths. A total of 12,552 patients were recuperated and released. An estimated number of 6242 cases already believed. Many of the victims (59,989 cases) were in the province of Hubei, where the epidemic originated, including 10,970 serious cases and 1789 deaths [22, 39]. Many important steps have been taken by the Government of China to counter the spread of COVID 19, which includes ban on public meeting, the construction of a major hospital in Wuhan especially for COVID-19 patients affected, delivering required medical supplies including labels, temperature thermometers, supplying free health care to COVID-19 people, gathering physical money cash from places with elevated rates of special case diseases and barring their movement to healthy regions, and lately providing incentives to staff working the healthcare places in particular [16, $21,45]$.

\section{The Covid-19}

Corona viruses are a large family of viruses that can cause animal or human disease. Several Corona viruses are known to cause respiratory infections in humans ranging from the common cold to more serious diseases such as Middle East Respiratory Syndrome (MERS) and Severe Acute Respiratory Syndrome (SARS). The most recent Corona virus found triggers the Corona virus disease. COVID-19 is an infectious disease caused by a Corona virus that was most recently discovered. This latest virus and disease was unknown in December 2019, until the epidemic began in Wuhan, China. While we are also studying how COVID-2019 affects patients, elderly people and those with pre-existing medical problems (such as high blood pressure, coronary failure, lung disease, asthma, or diabetes) tend to experience more often severe illness than others $[15,42]$. A schematic view of structure of corona virus and its structural specification is shown in Figure I and II respectively.

Table 1. List of Human Corona virus in chronological order.

\begin{tabular}{|c|c|c|c|c|}
\hline $\begin{array}{c}\text { Name of Human } \\
\text { Corona virus }\end{array}$ & Genus & Associated Symptoms & CFR & Founded \\
\hline (SARS-CoV-2) & & severe acute respiratory syndrome & $6.70 \%$ & 2019 \\
\hline [MERS-CoV] & & severe acute respiratory syndrome & $39 \%$ & 2012 \\
\hline HCoV-HKU1 & & pneumonia & $9.50 \%$ & 2005 \\
\hline HCoV-NL63 & & mild respiratory tract infection & $19.68 \%$ & 2004 \\
\hline SARS-CoV & & severe acute respiratory syndrome & $9.60 \%$ & 2002 \\
\hline HCoV-229E & & mild respiratory tract infection & $\%$ & 1960 's \\
\hline HCoV-OC43 & & mild respiratory tract infection & $\%$ & 1960 's \\
\hline \multicolumn{7}{|l|}{ Acronyms:CFR:Case Fatality Rate, RC: Recovery Rate } \\
\hline
\end{tabular}

Figure 1. Schematic view of structure of COVID-19.

Figure 2. Internal structure of COVID-19.
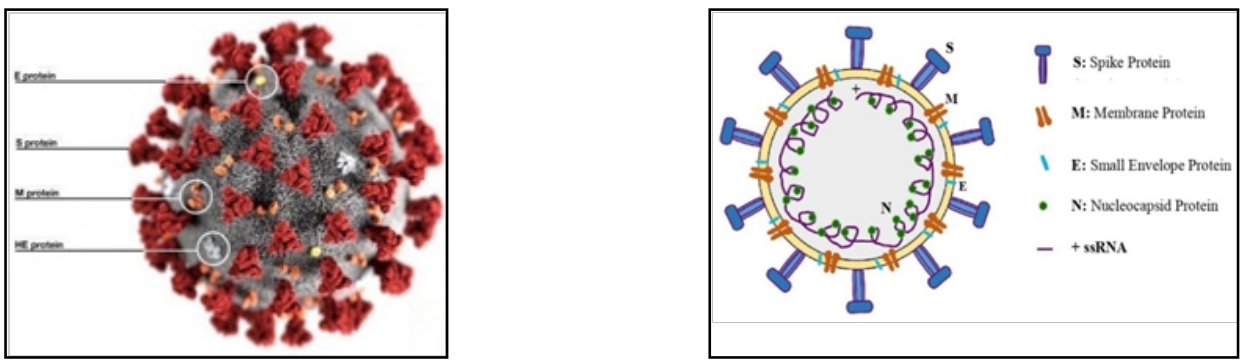
Information on COVID-19, the disease triggered by SARS$\mathrm{CoV}-2$, is continually developing in its seriousness and the extent of symptoms [40, 41]. The clinical findings recorded include fever (less severe than in SARS and MERS) and respiratory symptoms, most commonly dry cough. Certain results show radiological lung distortion in the ground-glass, regular or decreased concentrations of leukocytes and thrombocytes, hypoxemia, deranged liver, and renal activity.

\section{Transmission}

Investigations of how this virus originated and spread are continuing. It is noted that the virus that causes COVID-19 is transmitted mainly through droplets produced when a person who is infected coughs, sneezes or talks. These droplets are too heavy to remain in the rain. They crash quickly on floors or surfaces $[8,39]$. When someone is within 1 meter of a person with COVID-19 or touching a tainted surface and then rubbing your head, nose or mouth before washing your hands, then the person may become infected by breathing in the virus as shown in Figure III [23].

There are three different methods of spreading the virus namely human to human transmission, aerosol transmission, touch transmission (refer to Figure III). During coughing or sneezing the infection is believed to be spread to certain persons by respiratory droplets. Droplet transmission may occur when an infected individual sneezes or coughs, after which viruses that comprise droplets are carried through the air for up to 3 feet and released on the mucous membranes of the mouth, nose, or eyes of people nearby [38]. Recent research indicates the transmission is also possible through the ocular surface. Certain ways for virus transmission involve shaking hands with an infected human, contacting an infectious object/surface, repeated rubbing of the nose or lips, or interaction with the excreta of a patient. One method is "hidden transmission," where asymptomatic contaminated persons or carriers spread the virus to an unaware person unknowingly [24, 36].

\section{Transmission Factors}

Due to easyair travel human beings are now more versatile than ever before, which enables the movement of a pathogen around the globe in a matter of hours. More than 4 billion journeys are taken by air per year, and this rate of travel in an infectious and moving global population offers an unparalleled ability to grow and propagate rapidly [36]. In that context, COVID-19's timing had been quite poor luck. Chinese New Year is the world's biggest mass migration, with 385 million people taking nearly three billion holiday trips $[30,31]$. The occurrence of the outbreak atthis time makes it difficultto trace and control and certainly influences the speed at which it spreads. The outbreak of SARS-CoV-2 is a clear indication of the significance of regulating the unpredictable effects of globalizing the world in which we live. The desire to travel worldwide is of many of us, whose negative consequences result inchallenges such as carrying potential pathogens [37].

Health care infrastructure and human influences can also impact virus dissemination. The capability of the medical system comprises the factors, provision of medication or vaccination, and the range of services available for distribution (human, environmental, and financial) $[14,46]$. Other human factors are the population is immunologically naive or not, how effectively the human immune system will respond to the infection, population's age size, demographic composition, longevity and cultural behavior [42].

\section{Risk Factors}

The worldwide fatality rate of COVID-19 in a patient of age less than 18 years is $3.4 \%$.Individuals above 50 years of age and with medical disorders are at greater danger [9]. In over 80 years of individuals with a case-fatality rate of $21.9 \%$, the largest danger category. While we are also studying how COVID-2019 affects patients, elderly people and those with pre-existing medical problems such as high blood pressure, coronary failure, lung disease, asthma, or diabetes tend to experience more often severe illness than others. Risk factors for COVID-19 appear to include [25, $35,47]$.

- Recent travel or resident in a region of continuing COVID-19 population spread as determined by CDC or WHO.

- Near touch of someone with COVID-19, such as when a family member or health care provider is taking care of an infected person.

\section{Associated Symptoms}

The COVID-19 virus has various forms of influencing specific individuals. COVID-19 is a respiratory disorder and most of the affected patients experience mild to moderate symptoms and survive without any care being needed. In humans, symptoms can be seen within 14 days of virus exposure [26]. People with chronic medical issues and people of more than 60 have an elevated chance of developing chronic illness and death [35]. Some of the common symptoms are:

- Pyrexia(rise in body temperature)

- Fatigue

- Dry Cough.

- Dyspnea (shortness of breathing)

- Pains

- Pharyngitis

Figure 3. Modes of Corona Virus Transmission.

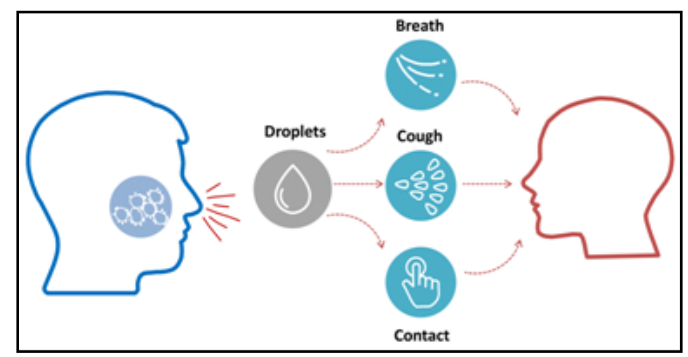




\section{- Nausea}

Those who experience mild symptoms should isolate themselves and consult their health care professional, or a COVID-19 support line. Figure IV shows some more common associated symptoms of COVID-19.

\section{Preventive Measures}

While the current Corona virus does not have a vaccine available to prevent infection, you should take measures to reduce the chance of infection. Following these steps, the WHO and CDC suggests stopping COVID-19 [10, 34]:

- Avoid large events and mass gatherings.

- Avoid close contact (within about 6 feet, or 2 meters) with anyone who is sick or has symptoms.

- Keep distance between yourself and others if COVID-19 is spreading in your community, especially if you have a higher risk of serious illness.

- Wash your hands often with soap and water for at least 20 seconds, or use an alcohol-based hand sanitizer that contains at least $60 \%$ alcohol.

- Cover your mouth and nose with your elbow or a tissue when you cough or sneeze. Throw away the used tissue.

- Avoid touching your eyes, nose and mouth.

- Avoid sharing dishes, glasses, bedding and other household items if you're sick.

- Wash the high-touch surfaces regularly and disinfect.

Following Figures show that how social distancing (such as following guidance of lockdown) reduced the risk of infection with a factor of monotonic half binary tree of the data structure [17].

When you are ill, stay home from college, school and public places, until you have medical attention. When you're sick stop using public transport. The CDC advises wearing cotton face coverings in public areas, including the grocery store, where direct contact with others is impossible to prevent $[27,36]$, especially in areas with continuing group spread it is suggested. This revised guidance is focused on evidence that shows that people with COVID-19 are likely to spread the virus until they know that they do. Public use of masks can help to reduce the spread of individuals who have no symptoms. Recommended for the public are nonmedical cotton masks [46].

\section{Stages Of Covid-19}

The Union Health Ministry has started intermittent surveillance of citizens who have had respiratory diseases such as influenza and pneumonia but do not have travel history abroad to determine if corona virus infection has spread to the population [47].

\section{The Stage I}

The stage one is also referred to as transported and sporadic cases or only those in places contaminated by virus record positive. At this stage of pandemic the disease doesn't spread locally, cases are reported by people who usually have had travel history to affected areas $[28,34]$.

\section{The Stage II}

Stage two (often called local transmission) is a pandemic era when there source of the transmission is detected and can be traced, usually with anyone similar to the individual, such as family or someone he/she has come into touch with [29]. Those who are reacting positively at this stage are the individuals who are performing positively at this level, particularly others who have travel history to the affected countries or are in close touch with those who have prior knowledge with getting a good COVID-19 patient.

\section{The Stage III}

Stage third or community transmission is a state of pandemic where it is not possible to locate the root of the virus because several locations are contaminated. It occurs when a person carries

Figure 4. Associated symptoms of COVID-19.

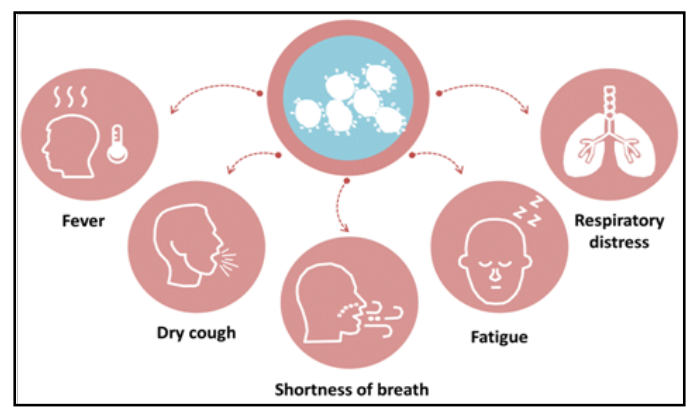

Figure 5. Transmission tree before social distancing.

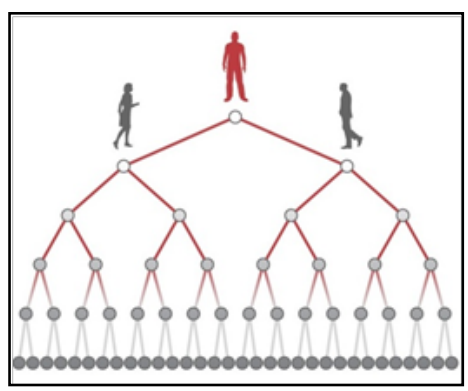

Figure 6. Transmission tree after social distancing.

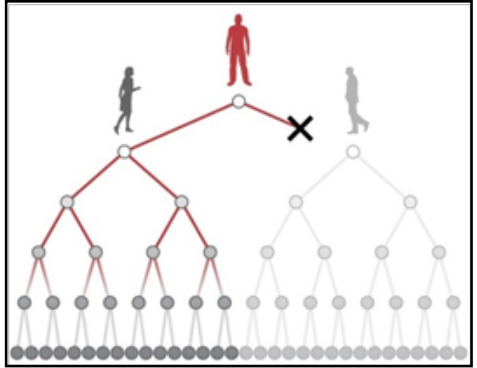


out positive testing without exposure to an infectious group or any travel history to a contaminated region $[12,33]$. Transmission to the Community recorded by Italy and Spain. This all depends on how much the countries are sealing their boundaries to control this issue. Countries like Italy and Spain are in at this stage. Before now, China has become the only country in the world to witness Stage 4 where distribution is nearly uncontrollable, with many big disease outbreaks $[32,44]$.

\section{The Stage IV}

Stage four is mainly deals when the outbreak is known as an epidemic or an event so severe that there is little clear end of the continued propagation where spread is practically uncontrollable. This stage is only experienced by China in the current case [30].

\section{Global Imapct Of Covid 19 Pandemic}

The COVID-19 pandemic is currently the major public health issue and the largest threat which the world is undergoing after World War II [11, 43]. The pandemic flies like a surge something that will devastate anyone not prepared strongly to deal with it. The pandemic is a significant public health threat, having reported 332,930 confirmed cases and 14,510 casualties all over the world till 23 March 2020. People all over the world are paying costs of the pandemic in the form of deaths of their loved ones and the emotional pain and anxiety felt by almost all. This is more than just a safety issue. It is a social, economic, and human crisis. The SARS-CoV-2 which is described as pandemic by WHO targets communities at its root $[36,41]$. People in every part of the world directly or indirectly experiencing the serious effects of this outbreak. COVID-19 impact advisories have been released by WHO and all member nations. The only solution to prevent the disease from spreading is isolation from external world which results in depression, anxious conditions which is also related to instability, economic recessions and severe emotional trauma. SociologistEric Kleinberg said, "We are undergoing a phase of social Pain. It is going to result in social misery associated with loneliness and social distancing that is discussed by very few of us [32].

\section{Data Collection}

To draw a meaningful conclusion from the pandemic, we compiled appropriate data on related COVID-19 indicators, including total confirmed cases, new cases reported every day, mortality rate and number of recovered patients from WHO'sdatabase, and compiled the records that provides a complete 90-day report (from 30 Jan 2020 to 28 April 2020) [29, 34, 41] as shown in Table II.

Table 2. Working model dataset of COVID-19 (GLOBAL).

\begin{tabular}{|c|c|c|c|c|c|c|c|}
\hline$\#$ & Case Reported on & Total Cases & New Cases & Total Death & New Death & $\begin{array}{c}\text { Risk } \\
\text { Assessment }\end{array}$ & SRN \\
\hline 0 & 21 Jan 2020 & 282 & 60 & 6 & 6 & - & 1 \\
\hline 1 & 22 Jan 2020 & 314 & 32 & 6 & 4 & - & 2 \\
\hline 2 & $23 \operatorname{Jan} 2020$ & 581 & 267 & 16 & 10 & - & 3 \\
\hline 3 & $24 \operatorname{Jan} 2020$ & 846 & 265 & 25 & 9 & - & 4 \\
\hline 4 & 25 Jan 2020 & 1320 & 474 & 41 & 16 & - & 5 \\
\hline 5 & $26 \operatorname{Jan} 2020$ & 2014 & 694 & 56 & 15 & - & 6 \\
\hline 6 & 27 Jan 2020 & 2798 & 784 & 80 & 24 & High & 7 \\
\hline 7 & $28 \operatorname{Jan} 2020$ & 4593 & 1795 & 106 & 26 & High & 8 \\
\hline 8 & 29 Jan 2020 & 6065 & 1472 & 132 & 26 & High & 9 \\
\hline 9 & 30 Jan 2020 & 7818 & 0 & 170 & 0 & High & 10 \\
\hline 10 & 31 Jan 2020 & 9826 & 0 & 213 & 0 & High & 11 \\
\hline 11 & $1 \mathrm{Feb} 2020$ & 11953 & 2128 & 259 & 46 & High & 12 \\
\hline 12 & 2 Feb 2020 & 14557 & 2604 & 305 & 45 & High & 13 \\
\hline 13 & 3 Feb 2020 & 17391 & 2838 & 362 & 57 & High & 14 \\
\hline 14 & 4 Feb 2020 & 20630 & 3241 & 426 & 64 & High & 15 \\
\hline 15 & 5 Feb 2020 & 24554 & 3925 & 492 & 66 & High & 16 \\
\hline 16 & 6 Feb 2020 & 28276 & 3722 & 565 & 73 & High & 17 \\
\hline 17 & 7 Feb 2020 & 31481 & 3205 & 638 & 73 & High & 18 \\
\hline 18 & 8 Feb 2020 & 34886 & 3419 & 724 & 86 & High & 19 \\
\hline 19 & 9 Feb 2020 & 37558 & 2676 & 813 & 89 & High & 20 \\
\hline 20 & 10 Feb 2020 & 40554 & 3085 & 910 & 97 & High & 21 \\
\hline 21 & 11 Feb 2020 & 43103 & 2560 & 1018 & 108 & High & 22 \\
\hline 22 & 12 Feb 2020 & 45171 & 2068 & 1115 & 97 & High & 23 \\
\hline 23 & 13 Feb 2020 & 46997 & 1826 & 1369 & 254 & High & 24 \\
\hline 24 & 14 Feb 2020 & 49053 & 2056 & 1383 & 122 & High & 25 \\
\hline 25 & 15 Feb 2020 & 50580 & 1527 & 1526 & 121 & High & 26 \\
\hline 26 & 16 Feb 2020 & 51857 & 1278 & 1669 & 143 & High & 27 \\
\hline 27 & 17 Feb 2020 & 71429 & 2162 & 1775 & 106 & High & 28 \\
\hline 28 & 18 Feb 2020 & 73332 & 1901 & 1873 & 98 & High & 29 \\
\hline 29 & 19 Feb 2020 & 75204 & 1872 & 2009 & 136 & High & 30 \\
\hline 30 & 20 Feb 2020 & 75748 & 548 & 2129 & 120 & High & 31 \\
\hline 31 & 21 Feb 2020 & 76769 & 1021 & 2247 & 118 & High & 32 \\
\hline
\end{tabular}




\begin{tabular}{|c|c|c|c|c|c|c|c|}
\hline 32 & 22 Feb 2020 & 77794 & 599 & 2359 & 112 & High & 33 \\
\hline 33 & 23 Feb 2020 & 78811 & 1017 & 2462 & 103 & High & 34 \\
\hline 34 & 24 Feb 2020 & 79331 & 715 & 2618 & 156 & High & 35 \\
\hline 35 & 25 Feb 2020 & 80239 & 908 & 2700 & 82 & High & 36 \\
\hline 36 & 26 Feb 2020 & 81109 & 871 & 2762 & 62 & High & 37 \\
\hline 37 & 27 Feb 2020 & 82294 & 1185 & 2804 & 42 & High & 38 \\
\hline 38 & 28 Feb 2020 & 83652 & 1358 & 2858 & 54 & Very High & 39 \\
\hline 39 & 29 Feb 2020 & 85403 & 1753 & 2924 & 66 & Very High & 40 \\
\hline 40 & 1 Mar 2020 & 87137 & 1739 & 2977 & 53 & Very High & 41 \\
\hline 41 & 2 Mar 2020 & 88948 & 1806 & 3043 & 66 & Very High & 42 \\
\hline 42 & 3 Mar 2020 & 90869 & 1922 & 3112 & 69 & Very High & 43 \\
\hline 43 & 4 Mar 2020 & 93091 & 2223 & 3198 & 86 & Very High & 44 \\
\hline 44 & 5 Mar 2020 & 95324 & 2232 & 3281 & 84 & Very High & 45 \\
\hline 45 & 6 Mar 2020 & 98192 & 2873 & 3380 & 99 & Very High & 46 \\
\hline 46 & 7 Mar 2020 & 101927 & 3735 & 3486 & 106 & Very High & 47 \\
\hline 47 & 8 Mar 2020 & 105586 & 3656 & 3584 & 98 & Very High & 48 \\
\hline 48 & 9 Mar 2020 & 109577 & 3993 & 3809 & 225 & Very High & 49 \\
\hline 49 & 10 Mar 2020 & 113702 & 4125 & 4012 & 203 & Very High & 50 \\
\hline 50 & 11 Mar 2020 & 118319 & 4620 & 4292 & 280 & Very High & 51 \\
\hline 51 & $12 \operatorname{Mar} 2020$ & 125260 & 6741 & 4613 & 321 & Very High & 52 \\
\hline 52 & 13 Mar 2020 & 132758 & 7499 & 4955 & 342 & Very High & 53 \\
\hline 53 & 14 Mar 2020 & 142534 & 9764 & 5392 & 437 & Very High & 54 \\
\hline 54 & 15 Mar 2020 & 153517 & 10982 & 5735 & 343 & Very High & 55 \\
\hline 55 & 16 Mar 2020 & 167515 & 13903 & 6606 & 862 & Very High & 56 \\
\hline 56 & 17 Mar 2020 & 179111 & 11525 & 7426 & 475 & Very High & 57 \\
\hline 57 & 18 Mar 2020 & 191127 & 15123 & 7807 & 786 & Very High & 58 \\
\hline 58 & 19 Mar 2020 & 209839 & 16556 & 8778 & 828 & Very High & 59 \\
\hline 59 & 20 Mar 2020 & 234073 & 24247 & 9840 & 1061 & Very High & 60 \\
\hline 60 & 21 Mar 2020 & 266073 & 32000 & 11183 & 1343 & Very High & 61 \\
\hline 61 & 22 Mar 2020 & 292142 & 26069 & 12783 & 1600 & Very High & 62 \\
\hline 62 & 23 Mar 2020 & 332930 & 40788 & 14509 & 1727 & Very High & 63 \\
\hline 63 & 24 Mar 2020 & 372755 & 39825 & 16231 & 1722 & Very High & 64 \\
\hline 64 & 25 Mar 2020 & 413467 & 40712 & 18433 & 2202 & Very High & 65 \\
\hline 65 & 26 Mar 2020 & 462684 & 49219 & 20834 & 2401 & Very High & 66 \\
\hline 66 & 27 Mar 2020 & 509164 & 46484 & 23335 & 2501 & Very High & 67 \\
\hline 67 & 28 Mar 2020 & 571659 & 62495 & 26493 & 3158 & Very High & 68 \\
\hline 68 & 29 Mar 2020 & 634813 & 63160 & 29891 & 3398 & Very High & 69 \\
\hline 69 & 30 Mar 2020 & 693282 & 58469 & 33106 & 3215 & Very High & 70 \\
\hline 70 & 31 Mar 2020 & 750890 & 57610 & 36405 & 3301 & Very High & 71 \\
\hline 71 & 1 Apr 2020 & 823626 & 72736 & 40598 & 4193 & Very High & 72 \\
\hline 72 & 2 Apr 2020 & 896475 & 72836 & 45525 & 4923 & Very High & 73 \\
\hline 73 & 3 Apr 2020 & 972303 & 75828 & 50321 & 4822 & Very High & 74 \\
\hline 74 & 4 Apr 2020 & 1051697 & 79394 & 56986 & 6665 & Very High & 75 \\
\hline 75 & 5 Apr 2020 & 1133758 & 82061 & 62784 & 5798 & Very High & 76 \\
\hline 76 & 6 Apr 2020 & 1210956 & 77200 & 67594 & 4810 & Very High & 77 \\
\hline 77 & 7 Apr 2020 & 1279722 & 68766 & 72614 & 5020 & Very High & 78 \\
\hline 78 & 8 Apr 2020 & 1353361 & 73639 & 79235 & 6695 & Very High & 79 \\
\hline 79 & 9 Apr 2020 & 1436198 & 82837 & 85521 & 6286 & Very High & 80 \\
\hline 80 & 10 Apr 2020 & 1521252 & 85054 & 92798 & 7277 & Very High & 81 \\
\hline 81 & 11 Apr 2020 & 1610909 & 89657 & 99690 & 6892 & Very High & 82 \\
\hline 82 & 12 Apr 2020 & 1696588 & 85679 & 105952 & 6262 & Very High & 83 \\
\hline 83 & 13 Apr 2020 & 1773084 & 76498 & 111652 & 5702 & Very High & 84 \\
\hline 84 & 14 Apr 2020 & 1844863 & 71779 & 117021 & 5369 & Very High & 85 \\
\hline 85 & 15Apr 2020 & 1914916 & 70082 & 123010 & 5989 & Very High & 86 \\
\hline 86 & 16Apr 2020 & 1991562 & 76647 & 130885 & 7875 & Very High & 87 \\
\hline 87 & 17Apr 2020 & 2074529 & 82967 & 139378 & 8493 & Very High & 88 \\
\hline 88 & 18Apr 2020 & 2160207 & 85678 & 146088 & 6710 & Very High & 89 \\
\hline 89 & 19Apr 2020 & 2241778 & 81572 & 152551 & 6463 & Very High & 90 \\
\hline & 90 days & 38532222 & 2224679 & 2168677 & 152649 & & \\
\hline
\end{tabular}

Acronym: SRN: Situation Report Number fetches from the repository of WHO. 


\section{Statistical Analysis}

In this section we have performed two rigorous statistical analysis of the data listed in the dataset. For each data point of the case, we have extracted a unique value is referred to as a model. Thus in total we have four model for statistical purpose. ANOVA, regression and standard deviation of the data has obtained.

Asymptotic growth analysis: In this test, we have primarily compared the rate of growth and decay of a model w.r.t. another one with a same time frame. The test has been conducted keeping with the number of confirm cases (model I) as an independent variable whereas the rest three are in dependent side. Figure VII (a), (b), (c) and (d) represents situations obtained from each model under the time frame of 90 days.

Dependent variable: Confirmed cases

Time series analysis: The time series analysis of the four cases w.r.t. the transformation difference factor $(\mathrm{tdf}=1)$ is carried out and following mix analysis graph is found (refer to Figure VIII). Each color shows a specific model of the cases which are further explained in this section. The mixed time series analysis is show $\mathrm{n}$ in Figure VIII. The free body diagram of analysis shown in this Figure is separately discussed in Figure IX, X, XI and XII.

\section{Model I: TOTAL CONFIRMED CASES}

As we can see in Index 2 (refer to the dataset) of model TOTAL CONFIRM CASES, the maximum impulse (by using equation (i)) achieved by this model is 85.03 and the minimum impulse is 0.66 which is indexed in \#34 of the dataset. The linear asymptotic growth rate of the model cases rises from 21 Jan 2020 to 19 April 2020 is represented in Figure IX.

Impulse $=\left(\frac{\operatorname{index}(i)-\operatorname{index}(i-1)}{\operatorname{index}(i-1)}\right) \times 100----(1)$
Figure 7(a). Asymptotic growth of confirmed case w.r.t. total death.

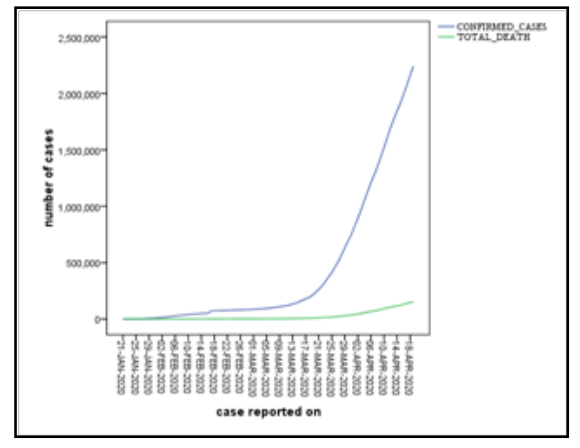

Figure 7(c). Asymptotic growth of total death w.r.t. new death.

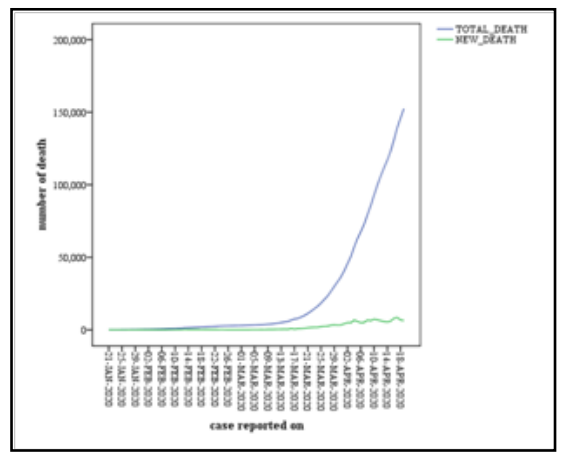

Figure 7(b). Asymptotic growth of confirmed case w.r.t. new cases.

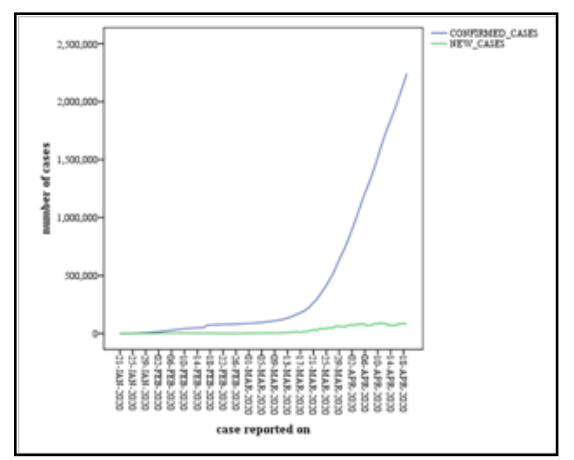

Figure 7(d). Asymptotic growth of new death w.r.t. new cases.

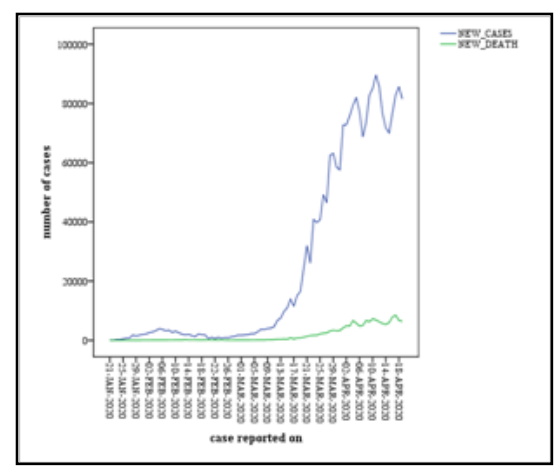

Figure 8. Mixed time series analysis of model I, II, III and IV.

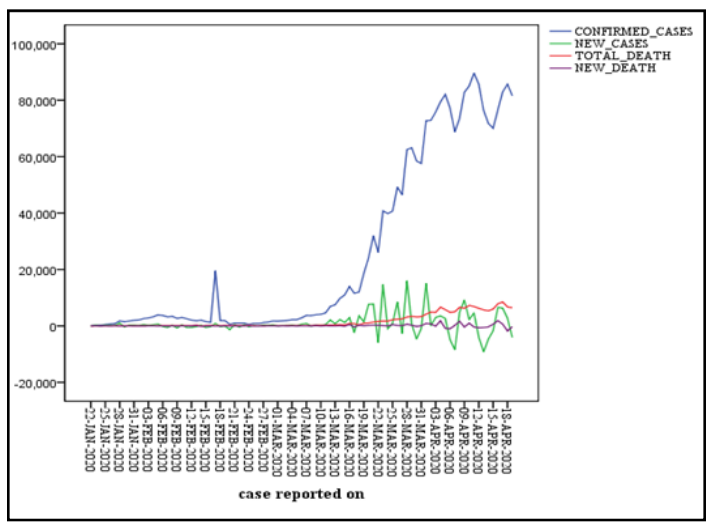


Figure 9. Time series analysis of model I.

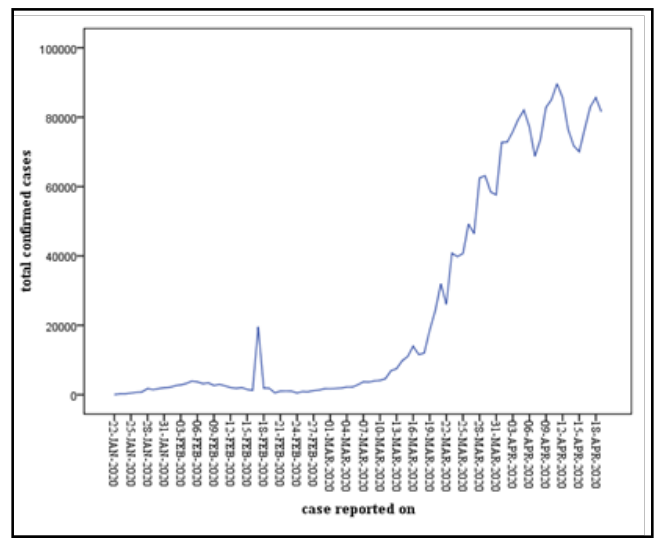

$L A G=\frac{U B-L B}{L B}=\frac{2241778-282}{2826}=7948.56$

Where LAG stands for linear asymptotic growth, UB for upper bound, and LB for lower bound. The standard deviation $(\sigma)$ of the model is calculated with the help of the expected growth rate and mean average growth rate as:

$\sigma_{X}=\sqrt{E(X)^{2}-(E(X))^{2}}$

Where $\mathrm{E}$ represents the expectation of the variable $\mathrm{X}$ (model) which is defined as:

$E(X)=\frac{\sum_{i=1}^{|X|} X_{i}}{|X|}$ if $|X|$ is represented as $\mathrm{n}$ then

$E(X)=\frac{\sum_{i=1}^{n} X_{i}}{n} \forall 0<i \leq 90$. So the standard deviation of the model

total confirmed cases is found as:

$E(X)^{2}=343.07$ and $(E(X))^{2}=11.40$, hence the standard deviation of the model is:

$\sigma_{X}=\sqrt{E(X)^{2}-(E(X))^{2}}$

$\sigma_{X}=\sqrt{343.07-(11.40)^{2}}$

$\sigma_{X}=\sqrt{343.07-129.96}$

$\sigma_{X}=\sqrt{213.11}$

$\sigma_{X}=14.59$

\section{Model II: NEW CASES}

As we can see in Index 2 (refer to the dataset) of model NEW CASES, the maximum impulse (by using equation (i)) achieved by this model is 734.38 and the minimum impulse is -70.73 which is indexed in \#30 of the dataset. The linear asymptotic growth rate of the model cases rises from 21 Jan 2020 to 19 April 2020 is represented in Figure X.

Now we got linear $L A G=1358.53$ (by using equation (ii)), the standard deviation $(\sigma)$ of the model new casesis calculated with the help of the expected growth rate and mean average growth rate by using the equation (iii) is found as:

$E(X)^{2}=6934.84$ and $(E(X))^{2}=17.70$, hence the standard deviation of the model is:

$$
\begin{aligned}
\sigma_{X} & =\sqrt{E(X)^{2}-(E(X))^{2}} \\
\sigma_{X} & =\sqrt{6934.84-(17.70)^{2}} \\
\sigma_{X} & =\sqrt{6934.84-313.29} \\
\sigma_{X} & =\sqrt{6621.55} \\
\sigma_{X} & =81.37
\end{aligned}
$$

\section{Model III: TOTAL DEATH CASES}

As we can see in Index 2 (refer to the dataset) of model TOTAL DEATH, the maximum impulse achieved by this model is 166.67 and the minimum impulse is 0.00 which is indexed in \#1 of the dataset. The linear asymptotic growth rate of the model cases rises from 21 Jan 2020 to 19 April 2020 is represented in Figure XI.

Now we got linear $\mathrm{LAG}=25424.16$ (by using equation (ii)), the standard deviation $(\sigma)$ of the model total death cases is calculated with the help of the expected growth rate and mean average growth rate by using the equation (iii) is found as:

$E(X)^{2}=554.16$ and $(E(X))^{2}=13.16$, hence the standard deviation of the model is:

$$
\begin{aligned}
\sigma_{X} & =\sqrt{E(X)^{2}-(E(X))^{2}} \\
\sigma_{X} & =\sqrt{554.16-(13.16)^{2}} \\
\sigma_{X} & =\sqrt{554.16-173.18} \\
\sigma_{X} & =\sqrt{380.98} \\
\sigma_{X} & =19.51
\end{aligned}
$$

\section{Model IV: NEW DEATH CASES}

As we can see in Index 23 (refer to the dataset) of model NEW DEATH, the maximum impulse achieved by this model is 161.86 and the minimum impulse is -51.97 which is indexed in \#24 of the dataset. The linear asymptotic growth rate of the model cases rises from 21 Jan 2020 to 19 April 2020 is represented in Figure XII.

Now we got linear $L A G=1076.16$ (by using equation (ii)), the standard deviation $(\sigma)$ of the model new death cases is calculated with the help of the expected growth rate and mean average growth rate by using the equation (iii) is found as: 
Table 3. TSA Report of total Confirmed cases (model I).

\begin{tabular}{|c|c|c|c|c|c|c|c|c|c|}
\hline \multirow{3}{*}{ Scope } & \multicolumn{2}{|c|}{ Period of Observation } & \multirow{3}{*}{ Span (days) } & \multicolumn{4}{|c|}{ Impulse (\%) } & \multicolumn{2}{|c|}{ Asymptotic Growth } \\
\hline & \multirow{2}{*}{ From } & \multirow{2}{*}{ To } & & \multicolumn{2}{|c|}{$\uparrow$ Max } & \multicolumn{2}{|c|}{$\downarrow$ Min } & \multirow{2}{*}{ Linear } & \multirow[b]{2}{*}{$x$} \\
\hline & & & & Value & Date & Value & Date & & \\
\hline GLOBAL & 21-Jan-20 & 19-Apr-20 & 90 & $85.03[\# 2]$ & 23-Jan-20 & $0.66[\# 34]$ & 24-Feb-20 & 7948.56 & 14.59 \\
\hline
\end{tabular}

Observation: We can observe from the statistical analysis report (Refer to Table III) that maximum and minimum growth rate of total confirmed cases are found as 85.03 and 0.66 respectively, which shows the difference in growth rate in 33 days (23 Jan 2020 and 24 Feb 2020). The linear and asymptotic growth of the model is found as 7948.56 and 14.59 respectively which signify that the linear asymptotic growth is $\sim 544.79$ times larger than the average asymptotic growth of the total confirmed cases occurred per day. We can conclude that the maximum impulse achieved by the model on 23 Jan 2020 is $\sim 5.82$ times larger than the average asymptotic growth rate of total confirmed cases which is $14.59 \%$ per day; however, the minimum impulse achieved on 24 Feb 2020 is 22.10 times lesser than the average asymptotic growth rate of the model.

Figure 10. Time series analysis of model II.

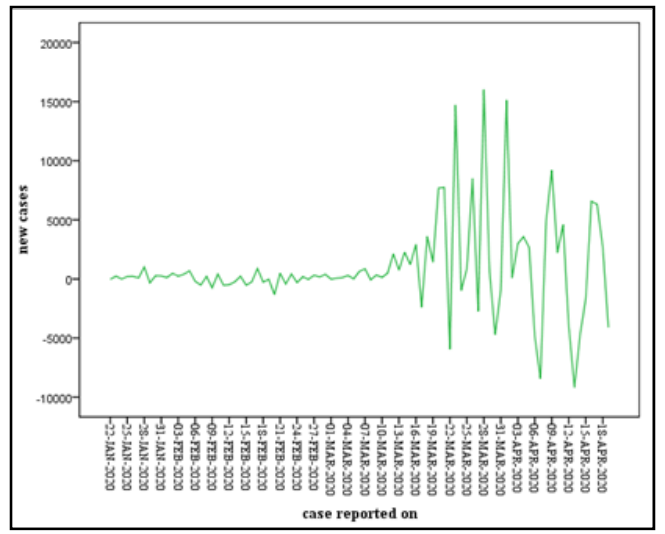

Table 4.TSA report of new cases (model II).

\begin{tabular}{|c|c|c|c|c|c|c|c|c|c|}
\hline \multirow{3}{*}{ Scope } & \multicolumn{2}{|c|}{ Period of Observation } & \multirow{3}{*}{$\begin{array}{c}\text { Span } \\
\text { (days) }\end{array}$} & \multicolumn{4}{|c|}{ Impulse $(\%)$} & \multicolumn{2}{|c|}{ Asymptotic Growth } \\
\hline & \multirow{2}{*}{ From } & \multirow{2}{*}{ To } & & \multicolumn{2}{|c|}{$\uparrow \operatorname{Max}$} & \multicolumn{2}{|c|}{$\downarrow$ Min } & \multirow{2}{*}{ Linear } & \multirow{2}{*}{$\sigma_{X}$} \\
\hline & & & & Value & Date & Value & Date & & \\
\hline GLOBAL & 21-Jan-20 & 19-Apr-20 & 90 & $734.38[\# 2]$ & 23-Jan-20 & $-70.73[\# 30]$ & 20-Feb-20 & 1358.53 & 81.37 \\
\hline
\end{tabular}

Observation: We can observe from the above statistical analysis report (Refer to Table IV) that the maximum and minimum growth rate of new cases is found as 734.38 and -70.73 respectively, which shows the variance of growth rate in 29 days (23 Jan 2020 and 20 Feb 2020). The linear and asymptotic growth of the model is found as 1358.53 and 81.37 respectively which signify that the linear asymptotic growth is $\sim 16.69$ times larger than the average asymptotic growth of the new cases occurred per day. We can conclude that the maximum impulse achieved by the model on 23 Jan 2020 is $\sim 9.02$ times greater than the average asymptotic growth rate of new cases which is $81.37 \%$ per day; however, the minimum impulse achieved on 20 Feb 2020 is only $\sim-0.86$ times slighter than the average asymptotic growth rate of the model.

Figure 11. Time series analysis of model III.

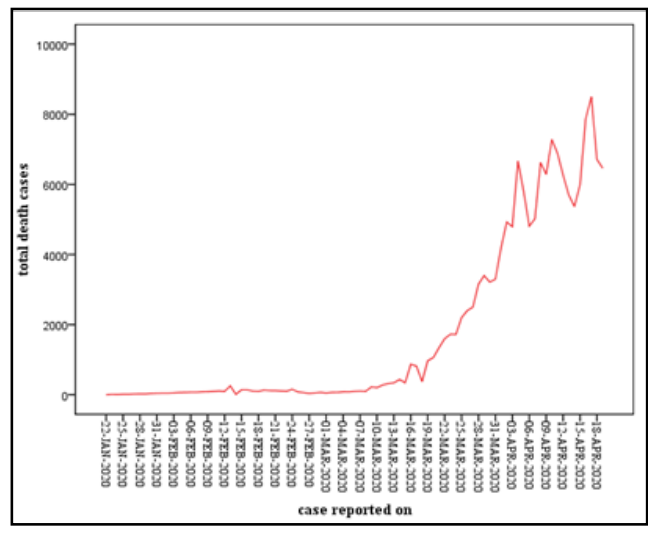

$E(X)^{2}=1549.57$ and $(E(X))^{2}=13.02$, hence the standard deviation of the model is:

\section{Results and Discussion}

$\sigma_{X}=\sqrt{E(X)^{2}-(E(X))^{2}}$

$\sigma_{X}=\sqrt{1549.57-(13.02)^{2}}$

$\sigma_{X}=\sqrt{1549.57-169.52}$

$\sigma_{X}=\sqrt{1380.05}$

$\sigma_{X}=37.14$

As we can see from the observation (refer to section B of part VI) the displacement and parity of maxima or minima parity impulse (expected fluctuation per day) of each model is listed in Table VII. 
Table 5. TSA report of total death cases (model III).

\begin{tabular}{|c|c|c|c|c|c|c|c|c|c|}
\hline \multirow{3}{*}{ Scope } & \multicolumn{2}{|c|}{ Period of Observation } & \multirow{3}{*}{$\begin{array}{l}\text { Span } \\
\text { (days) }\end{array}$} & \multicolumn{4}{|c|}{ Impulse (\%) } & \multicolumn{2}{|c|}{$\begin{array}{c}\text { Asymptotic Growth } \\
\%\end{array}$} \\
\hline & \multirow{2}{*}{ From } & \multirow{2}{*}{ To } & & \multicolumn{2}{|c|}{ Max } & \multicolumn{2}{|c|}{ Min } & \multirow{2}{*}{ Linear } & \multirow[b]{2}{*}{$\sigma_{X}$} \\
\hline & & & & Value & Date & Value & Date & & \\
\hline GLOBAL & 21-Jan-20 & 19-Apr-20 & 90 & $166.67[\# 2]$ & 23-Jan-20 & $0.00[\# 1]$ & 22-Jan-20 & 25424.16 & 19.51 \\
\hline
\end{tabular}

Observation: We can observe from above statistical analysis report (Refer to Table V) that maximum and minimum growth rate of total death cases are found as 166.67 and 0.00 respectively, which shows an immediate fluctuation of the rate of growth in total death cases in two consecutive days (23 Jan 2020 and 22 Jan 2020 ). The linear and asymptotic growth of the model is found as 25424.16 and 19.51 respectively which signify that the linear asymptotic growth is $\sim 1303.13$ times more fatal than the average asymptotic growth of the total death case occurred per day. We can conclude that the maximum impulse achieved by the model on 23 Jan 2020 is $\sim 8.54$ times larger than the average asymptotic growth rate of total death cases which is $19.51 \%$ per day; however, no potential comparison exists between the minimum impulse achieved on 22 Jan 2020 and average asymptotic growth rate of the model.

Figure 12. Time series analysis of model IV.

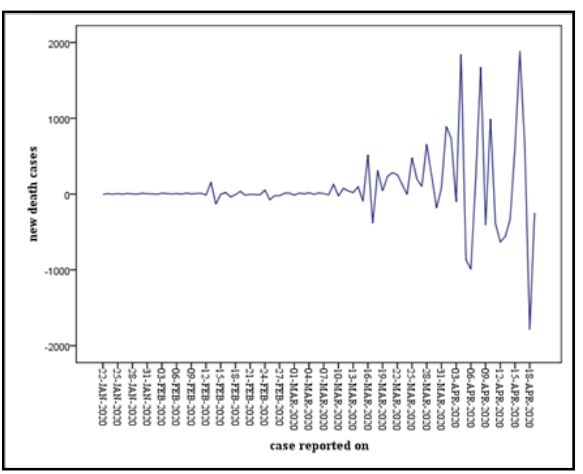

Table 6. TSA report of new death cases (model IV).

\begin{tabular}{|c|c|c|c|c|c|c|c|c|c|}
\hline \multirow{3}{*}{ Scope } & \multicolumn{2}{|c|}{ Period of Observation } & \multirow{3}{*}{$\begin{array}{c}\text { Span } \\
\text { (days) }\end{array}$} & \multicolumn{4}{|c|}{ Impulse (\%) } & \multicolumn{2}{|c|}{ Asymptotic Growth } \\
\hline & \multirow{2}{*}{ From } & \multirow{2}{*}{ To } & & \multicolumn{2}{|c|}{ Max } & \multicolumn{2}{|c|}{ Min } & \multirow{2}{*}{ Linear } & \multirow[b]{2}{*}{$\sigma_{X}$} \\
\hline & & & & Value & Date & Value & Date & & \\
\hline GLOBAL & 21-Jan-20 & 19-Apr-20 & 90 & $161.86[\#: 23]$ & 13-Feb-20 & -51.97 [\#:24] & 14-Feb-20 & 1076.16 & 37.14 \\
\hline
\end{tabular}

Observation: We can observe from above statistical analysis report (Refer to Table VI) that maximum and minimum growth rate of new death cases are found as 161.86 and -51.97 respectively, which shows a rapid fluctuation of growth rate in two consecutive days (13 Feb 2020 and 14 Feb 2020 ). The linear and asymptotic growth of the model is found as 1076.16 and 37.14 respectively which signify that the linear asymptotic growth is $\sim 28.97$ times strong than the average asymptotic growth of the new death case occurred per day. We can conclude that the maximum impulse achieved by the model on 13 Feb 2020 is $\sim 4.35$ times larger than the average asymptotic growth rate of new death cases which is $37.14 \%$ per day; however, the minimum impulse achieved on 14 Feb 2020 is -1.39 times lesser than the average asymptotic growth rate of the model.

Table 7. Summarized value of displacement and expected parity index.

\begin{tabular}{|c|c|c|c|c|c|c|}
\hline \multirow{2}{*}{ \#Model } & \multirow{2}{*}{$\begin{array}{l}\text { Model } \\
\text { Name }\end{array}$} & \multicolumn{2}{|c|}{ Observed Fluctuation } & \multirow{2}{*}{$\begin{array}{c}\text { Span } \\
\text { (days) }\end{array}$} & \multirow{2}{*}{$\begin{array}{l}\text { Displace- } \\
\text { ment }\end{array}$} & \multirow{2}{*}{$\begin{array}{c}\text { Expected } \\
\text { Parity Index }\end{array}$} \\
\hline & & Maxima & Minima & & & \\
\hline $\mathrm{I}$ & $\begin{array}{l}\text { Total con- } \\
\text { firmed cases }\end{array}$ & 85.03 & 0.66 & 33 & 85.69 & 2.59 \\
\hline II & New cases & 734.38 & -70.23 & 29 & 805.11 & 27.76 \\
\hline III & Total death & 166.67 & 0 & 2 & 166.67 & 83.33 \\
\hline IV & New death & 161.86 & -51.97 & 2 & 213.83 & 106.91 \\
\hline
\end{tabular}

The results shown in the above table suggest that an Expected Parity Index (EPI) (maxima or minima degree of fluctuations attain by the model) is the maximum at model IV (new death cases) and is the minimum at the model I (total confirmed cases) of the pandemic. However till 19 April 2020 , no cases are found that overtake the obtained expected parity index value in each case. Obtained EPI suggests that a strong expected fluctuation might be possible in model IV (new death) whereas the model I (total confirmed cases) have the least expected fluctuation rate in the near future.

\section{Conclusion}

This paper presents a mathematical simulation of the novel corona virus (2019-nCoV) that has recently appeared in Wuhan China. We provided a brief description on the tools available that occur in infection generation and developed the mathematical model.
In this paper, we create a probabilistic model for estimating the probability of a major outbreak in a targeted region. The paper discusses some basic concepts, problems and remedial steps towards the outbreak of novel corona virus pandemic. Beside it, I have also performed rich data collection to perform some statistical tests to analyze the current situation and to predict the 
fore-coming scenario of the transmission. Results of regression testing like ANOVAs, variance, standard deviation and asymptotic growth rate of case provides a meaningful results that can further be use to draw some fact. Time series analysis report of the models provides a clear and concise root of the transmission pattern with respect to the day of the reported case. These reportswill help the researchers to take some prevention measures of the fore-coming pandemic situation.Growth rate of the cases can be used to predict the future situation with respect to their cause of transmission. The results of maximum and minimum impulse achieved by the time series analysis will help the researchers to correlate the activity done by the patients or suspected on the day of extreme fluctuations. The results of asymptotic growth show that total number of death cases is always upper bounded by the number of new cases, whereas the total confirmed cases and exponentially upper bounded by the number of rest all cases. In the span between 21 Jan 2020 to 10 March 2020, new cases, new death cases and total number of death cases are shows a linear to non-increasing rate of growth globally, after that, it undergoes into a monotonic non-increasing to increase rate of growth from 10 March 2020 to 25 March 2020 and then it grow exponentially. The initial values indicate some stability of the endemic while the equilibrium of the endemic changes to pandemic after 13 March 2020 and becomes asymptotically unstable.

\section{Acknowledgements}

I would like to pay my sincere thanks and gratefulness to my academic advisor Mr. Shabbir Hassan, whose constant encouragement and support acted as an impetus for working hard and completing this paper with sincerity. Also, I would like to pay my heartiest gratitude to my family and to my alma mater, Department of Social Work, Aligarh Muslim University for their unforgettable support whenever I needed. There are no words that can express gratitude for their love, affection and patience. They always stood by my side, had faith in my work and always prayed for my success.

Dedication: The paper is written in memory of my deceased father the whole work, efforts and outcome of this research article is dedicated to him.

\section{References}

[1]. Rajendra GA, Ghume VK, Merekar AN, Dokhe MD. Corona Virus 2019: Introduction and Its Treatments. IJRAR-International Journal of Research and Analytical Reviews (IJRAR). 2020; 7(1): 522-530.

[2]. Xiang YT, Li W, Zhang Q, Jin Y, Rao WW, Zeng LN, et al. Timely research papers about COVID-19 in China. The Lancet. 2020; 395(10225): 684685. PMID: 32078803.

[3]. Greene CJ, Burleson SL, Crosby JC, Heimann MA, Pigott DC. Coronavirus disease 2019: International public health considerations. Journal of the American College of Emergency Physicians Open. 2020; 1(2):70-7.

[4]. Yan R, Zhang Y, Li Y, Xia L, Guo Y, Zhou Q. Structural basis for the recognition of SARS-CoV-2 by full-length human ACE2. Science. 2020; 367(6485): 1444-1448. PMID: 32132184.

[5]. Liu Y, Gayle AA, Wilder-Smith A, Rocklöv J. The reproductive number of COVID-19 is higher compared to SARS coronavirus. Journal of travel medicine. 2020; 27(2):taaa021. PMID: 32052846.

[6]. Definition of Corona by Merriam-Webster, Merriam-Webster, archived from the original on 2020-03-24, retrieved 2020-03-24.

[7]. Neuman BW, Kiss G, Kunding AH, Bhella D, Baksh MF, Connelly S, et al. A structural analysis of $\mathrm{M}$ protein in coronavirus assembly and morphology. Journal of structural biology. 2011; 174(1), 11-22. PMID: 21130884.

[8]. Singhal T. A review of coronavirus disease-2019 (COVID-19). The Indian
Journal of Pediatrics. 2020; 1-6.

[9]. Allcott H, Boxell L, Conway J, Gentzkow M, Thaler M, Yang DY. Polarization and public health: Partisan differences in social distancing during the coronavirus pandemic. NBER Working Paper. 2020; (w26946).

[10]. Patel AB, Verma A. COVID-19 and angiotensin-converting enzyme inhibitors and angiotensin receptor blockers: what is the evidence?. Jama. 2020; 323(18):1769-1770. PMID: 32208485.

[11]. Peiris JS, Yuen KY, Osterhaus AD, Stöhr K. The severe acute respiratory syndrome. New England Journal of Medicine. 2003; 349(25): 2431-2441. PMID: 14681510.

[12]. Maier HJ, Bickerton E, Britton P. Coronaviruses: methods and protocols. Springer Berlin. 2015.

[13]. Malik M, Elkholy AA, Khan W, Hassounah S, Abubakar A, Minh NT, et al. Middle East respiratory syndrome coronavirus: current knowledge and future considerations. EMHJ-Eastern Mediterranean Health Journal. 2016; 22(7): 537-546. PMID: 27714748.

[14]. Lu CW, Liu XF, Jia ZF. 2019-nCoV transmission through the ocular surface must not be ignored. Lancet. 2020; 395(10224): e39. PMID: 32035510.

[15]. Rocklöv J, Sjödin H, Wilder-Smith A. COVID-19 outbreak on the Diamond Princess Cruise ship: estimating the epidemic potential and effectiveness of public health countermeasures. Journal of travel medicine. 2020. 27(3): taaa030. PMID: 32109273.

[16]. Nishiura H, Linton NM, Akhmetzhanov AR. Initial cluster of novel coronavirus (2019-nCoV) infections in Wuhan, China is consistent with substantial human-to-human transmission. J Clin Med. 2020 Feb 11; 9(2): 488. PMID: 32054045.

[17]. MU Bokhari, Shabbir Hassan. Design of a Lightweight Stream Cipher: BOKHARI 256. International Journal of Engineering Research \& Technology (IJERT). 2020; 9(03).

[18]. Schweickert WD, Pohlman MC, Pohlman AS, Nigos C, Pawlik AJ, Esbrook CL, et al. Early physical and occupational therapy in mechanically ventilated, critically ill patients: a randomised controlled trial. The Lancet. 2009; 373(9678): 1874-1882. PMID: 19446324.

[19]. Asbury K, Fox L, Deniz E, Code A, Toseeb U. How is COVID-19 affecting the mental health of children with Special Educational Needs and Disabilities and their families?. J Autism Dev Disord. 2020; 1-9. PMID: 32737668.

[20]. Yang Y, Peng F, Wang R, Guan K, Jiang T, Xu G, et al. The deadly coronaviruses: The 2003 SARS pandemic and the 2020 novel coronavirus epidemic in China. Journal of autoimmunity. 2020; 109: 102434. PMID: 32143990.

[21]. Weiss SR, Navas-Martin S. Coronavirus pathogenesis and the emerging pathogen severe acute respiratory syndrome coronavirus. Microbiol. Mol. Biol. Rev. 2005; 69(4): 635-664. PMID: 16339739.

[22]. Fehr AR, Perlman S. Coronaviruses: an overview of their replication and pathogenesis. Methods Mol Biol. 2015; 1282: 1-23. PMID: 25720466.

[23]. Zhao L, Jha BK, Wu A, Elliott R, Ziebuhr J, Gorbalenya AE, et al. Antagonism of the interferon-induced OAS-RNase L pathway by murine coronavirus ns 2 protein is required for virus replication and liver pathology. Cell host \& microbe. 2012; 11(6): 607-616. PMID: 22704621.

[24]. Zumla A, Chan JF, Azhar EI, Hui DS, Yuen KY. Coronaviruses-drug discovery and therapeutic options. Nature reviews Drug discovery. 2016; 15(5): 327-47. PMID: 26868298.

[25]. Lu H, Stratton CW, Tang YW. Outbreak of Pneumonia of Unknown Etiology in Wuhan China: the Mystery and the Miracle. Journal of Medical Virology. 2020 Apr; 92(4): 401-402. PMID: 31950516.

[26]. Munster VJ, Koopmans M, van Doremalen N, van Riel D, de Wit E. A novel coronavirus emerging in China-key questions for impact assessment. New England Journal of Medicine. 2020; 382(8): 692-694. PMID: 31978293.

[27]. Kaner J, Schaack S. Understanding Ebola: the 2014 epidemic. Globalization and health. 2016 Dec; 12(1): 1-7.

[28]. Plourde AR, Bloch EM. A literature review of Zika virus. Emerging infectious diseases. 2016; 22(7): 1185-92. PMID: 27070380.

[29]. Gostin L, Phelan A, Coutinho AG, Eccleston-Turner M, Erondu N, Filani O, et al. Ebola in the Democratic Republic of the Congo: time to sound a global alert?. The Lancet. 2019; 393(10172): 617-620. PMID: 30732850.

[30]. Chen Q, Quan B, Li X, Gao G, Zheng W, Zhang J, et al. A report of clinical diagnosis and treatment of nine cases of coronavirus disease 2019. Journal of medical virology. 2020; 92(6): 683-687. PMID: 32162699.

[31]. Huang C, Wang Y, Li X, Ren L, Zhao J, Hu Y, et al. Clinical features of patients infected with 2019 novel coronavirus in Wuhan, China. The Lancet. 2020; 395(10223): 497-506

[32]. Lillie PJ, Samson A, Li A, Adams K, Capstick R, Barlow GD, et al. Novel coronavirus disease (Covid-19): the first two patients in the UK with person to person transmission. Journal of Infection. 2020. 80(5): 578-606. PMID: 32119884.

[33]. Hilgenfeld R, Peiris M. From SARS to MERS: 10 years of research on highly pathogenic human coronaviruses. Antiviral research. 2013; 100(1): 286295. PMID: 24012996. 
[34]. Fehr AR, Channappanavar R, Perlman S. Middle East respiratory syndrome: emergence of a pathogenic human coronavirus. Annual review of medicine. 2017; 68: 387-399. PMID: 27576010.

[35]. Marra MA, Jones SJ, Astell CR, Holt RA, Brooks-Wilson A, Butterfield YS, et al. The genome sequence of the SARS-associated coronavirus. Science. 2003; 300(5624): 1399-1404. PMID: 12730501.

[36]. Hassan S, Bokhari MU. Computing in Cryptography. In 2016 3rd International Conference on Computing for Sustainable Global Development (INDIACom). IEEE. 2016 Mar 16; 3941-3946.

[37]. Cyranoski D. Did pangolins spread the China coronavirus to people. Nature. $2020 \mathrm{Feb} ; 10$

[38]. Wang D, Hu B, Hu C, Zhu F, Liu X, Zhang J, et al. Clinical characteristics of 138 hospitalized patients with 2019 novel coronavirus-infected pneumonia in Wuhan, China. Jama. 2020; 323(11): 1061-1069. PMID: 32031570.

[39]. Owolabi KM, Atangana A. On the formulation of Adams-Bashforth scheme with Atangana-Baleanu-Caputo fractional derivative to model chaotic problems. Chaos. 2019; 29(2): 023111. PMID: 30823722.

[40]. Naik PA, Zu J, Owolabi KM. Modeling the mechanics of viral kinetics under immune control during primary infection of HIV-1 with treatment in fractional order. Physica A: Statistical Mechanics and its Applications. 2020; 545: 123816.

[41]. Smith KF, Goldberg M, Rosenthal S, Carlson L, Chen J, Chen C, et al. Global rise in human infectious disease outbreaks. Journal of The Royal So- ciety Interface. 2014; 11(101): 20140950. PMID: 25401184.

[42]. Jones KE, Patel NG, Levy MA, Storeygard A, Balk D, Gittleman JL, et al. Global trends in emerging infectious diseases. Nature. 2008; 451(7181): 990-993. PMID: 18288193.

[43]. Zaki AM, Van Boheemen S, Bestebroer TM, Osterhaus AD, Fouchier RA. Isolation of a novel coronavirus from a man with pneumonia in Saudi Arabia. New England Journal of Medicine. 2012; 367(19): 1814-1820. PMID: 23075143.

[44]. Lu L, Liu Q, Du L, Jiang S. Middle East respiratory syndrome coronavirus (MERS-CoV): challenges in identifying its source and controlling its spread. Microbes and infection. 2013; 15(8-9): 625-629. PMID: 23791956.

[45]. Huang C, Wang Y, Li X, Ren L, Zhao J, Hu Y, et al. Clinical features of patients infected with 2019 novel coronavirus in Wuhan, China. The Lancet. 2020; 395(10223): 497-506.

[46]. Bokhari MU, Hassan S. A comparative study on lightweight cryptography. In Cyber Security. Springer, Singapore. 2018; 69-79.

[47]. World Health Organization (WHO). WHO statement regarding cluster of pneumonia cases in Wuhan, China. Beijing. 2020; 9.

[48]. Borges do Nascimento IJ, Cacic N, Abdulazeem HM, von Groote TC, Jayarajah U, Weerasekara I, et al. Novel Coronavirus Infection (COVID-19) in Humans: A Scoping Review and Meta-Analysis. Journal of Clinical Medicine. 2020; 9(4): 941. PMID: 32235486. 